\title{
SOCIAL STRUCTURE, REASONABLE GAIN, AND ENTREPRENEURSHIP IN AFRICA
}

\section{GERARD GEORGE}

Dean and Professor of Innovation and Entrepreneurship

Lee Kong Chian School of Business

Singapore Management University

Singapore 178899

ggeorge@smu.edu.sg

\author{
REDDI KOTHA \\ Assistant Professor \\ Lee Kong Chian School of Business \\ Singapore Management University \\ Singapore 178899 \\ reddikotha@smu.edu.sg
}

PRITI PARIKH

Lecturer, Dept of Civil, Environ. \& Geomatic Eng.

University College London

117 Chadwick Building

London, UK

priti.parikh@ucl.ac.uk

TUFOOL ALNUAIMI

Assistant Professor of Data Science and Innovation

Imperial College London

London, UK, SW7 2AZ

t.al-nuaimi08@imperial.ac.uk

\section{ABUBAKR S. BAHAJ}

Professor and Head of the Energy \& Climate Change Division

University of Southampton

Southampton, UK, SO17 1BJ

A.S.Bahaj@soton.ac.uk

Accepted for publication on 24 February 2015 at Strategic Management Journal

The authors thank Rich Bettis and two anonymous reviewers for their constructive comments and guidance. We are grateful to UK's EPSRC and DFID for their grant (EP/G06394X/1) for replication of rural decentralized off-grid electricity generation through technology and business innovation. The first author also acknowledges the support of ESRC Professorial Fellowship on resource constrained innovation and inclusive growth (RES-051-27-0321). 


\title{
SOCIAL STRUCTURE, REASONABLE GAIN, AND ENTREPRENEURSHIP IN AFRICA
}

\begin{abstract}
In the context of desperate poverty, characterized by households at subsistence level that experience economic loss and social fracture, explanations for why individuals undertake entry into entrepreneurship are limited. We find that individuals rely on their social relationships to enable entrepreneurial activities that have the potential to create a reasonable income gain. In a sample of 1,049 households in rural Kenya, we test whether the disintegration of social structure attenuates entrepreneurial behavior. When coupled with factors such as income loss, gender of the household head, and access to communal resources, social structure plays a pivotal role in entrepreneurial action. We propose that the search for reasonable income gain is a key driver of entrepreneurial action at subsistence levels, thereby adding to behavioral explanations of entrepreneurship.
\end{abstract}

KEY WORDS: Entrepreneurship, Africa, Entry, Reasonable Gain, Affordable Loss, Effectuation, Poverty, Mobility, Occupational Change, Gender, Women 


\section{INTRODUCTION}

Individuals are embedded in webs of social relationships that both enable and constrain their actions and choices. Scholars have therefore focused on the effect of familial ties and kinship on entrepreneurial activity (Ruef, Aldrich and Carter, 2003). Although family structure affects entrepreneurial outcomes in all contexts, its role in traditional, patriarchal societies is especially prominent. Consistent with entrepreneurship in Western settings, studies in Africa have found that family ties play a prominent role in entrepreneurs' ability to access resources and the subsequent performance of their ventures (e.g., Khavul, Bruton and Wood, 2009; Khayesi and George, 2011). In the African context, kinship has extraordinary importance as a source of physical, emotional, and social stability (Khayesi, George and Antonakis, 2014; Kiggundu, 2002). Thus, the stability of an individual's family and social ties is likely to substantively influence his or her decision to engage in entrepreneurship. However, the rural African context is often characterized by social structure instability: environmental factors such as drought, disease, and death can readily and rapidly upend a household. Despite this disintegration of social structure, entrepreneurship appears to flourish in contexts of desperate poverty, raising questions on why kinship matters, and when it matters most.

Individuals committed to the pursuit of entrepreneurship must conclude that their rewards, however undefined, will outweigh the costs of their efforts (Knight, 1921; Sarasvathy, 2001). Prospect theory arguments suggest that individuals' decisions to engage in risk-taking activities is influenced not only by expected returns, but also by where the outcome of a risky decision will leave them, relative to a predetermined reference point (Kahneman and Tversky, 1979). In prospect theory, the threat of likely loss and the opportunity for potential gain are two distinct mechanisms affecting whether an individual engages in risky actions (e.g., March and Shapira, 1992). Studies from the developed world have suggested that when an individual's social structure disintegrates, his or her ability to start a new business is whittled away; in other words, an individual will perceive a reduction in the stock of resources available to wager, lose, and still 
survive, also referred to as affordable loss (Dew, Sarasvathy, Read and Wiltbank, 2009). In conditions of desperate poverty, however, social disintegration may also give rise to a desire to shore-up the economic position of the household by any means possible. As the consequence of inaction could include starvation, individuals may be motivated to search for new opportunities with the potential to provide a reasonable income gain. Thus, in contexts of desperate poverty, the calculus of affordable loss may well be supplanted by the opportunity logic of potential gain.

In the developed world, empirical evidence has suggested that family and social structure (Aldrich and Cliff, 2003), wealth endowment (Evans and Jovanovich, 1989), and access to social resources (Kotha and George, 2012) are substantive predictors of entry into entrepreneurship. How these traditional drivers affect affordable loss or reasonable gain and the subsequent efforts at business creation is beginning to receive theoretical attention (Dew et al., 2009; Sarasvathy, 2001). We explore the social and structural factors that affect entrepreneurial behavior in the context of desperate poverty by asking, Under what conditions does social structure disintegration hinder or hasten entry into entrepreneurship? In so doing, we explore how socio-economic losses affect household heads' tendency of whether to engage in entrepreneurial activity under conditions of severe duress. We develop predictions of how the relationship between social structure disintegration and entry into entrepreneurship is influenced by three structural factors: income, gender, and communal resources. We find that when social structure loss is accompanied by: (1) a large loss in household income hinders entry into entrepreneurship, but a small loss enables entry, (2) a change in family stability that causes a woman to become the head of the household increases entry, and (3) access to communal resources increases entry. We suggest that the factors of income, gender, and community resources should be jointly considered with the household's social structure disintegration to determine the outcome of entrepreneurial behavior. Figure 1 offers a summary of our model.

INSERT FIGURE 1 HERE 


\section{SOCIAL STRUCTURE, AFFORDABLE LOSS AND REASONABLE GAIN}

The typical unit of analysis in our research context is a household, because households typically jointly own property and clear property rights with explicit title deeds often do not exist. In a patriarchal society such as Kenya, households are often headed by the oldest economically active male member. In the event of his death or severe incapacitation, his spouse becomes the household head. In conditions of extreme poverty, natural calamities and macroeconomic shocks can have deleterious effects on individual and family welfare. For example, in Ethiopia, rural households are affected by shocks such as death, serious illness, price shocks on inputs and output, crop pests, and crime. The Ebola epidemic in West Africa is another example where thousands of families have had their lives torn apart. These shocks reduce household income and increase vulnerability, forcing families into destitution (Dercon, 2004).

Consider the case of a society in which the average household is at subsistence level. Such a household presumably has no further resources it can afford to lose, as any loss could trigger the imminent threat of starvation. As a household's social structure-defined as family and community relationships - disintegrates, it triggers a frantic search for new income sources. Consequently, individuals explore opportunities that have the potential, however marginal, for a positive return on their effort, which we refer to as reasonable gain. Consistent with the reasonable gain mechanism, there is ample empirical evidence from the Global Entrepreneurship Monitor (GEM) studies confirming that entrepreneurial efforts in Sub-Saharan Africa are many times more prevalent than in developed countries (Reynolds, et al., 2005). Evidence supporting the reasonable gain mechanism comes from studies on transition economies, wherein households that suffer crises are more likely to start a new business, especially if the household head loses employment (Paul \& Sarma, 2013). Therefore, under conditions of desperate poverty, when adult earning members in a household die or are severely incapacitated, remaining household members are more likely to seek out avenues to fill the void. 
Individuals do not hesitate to take on uncertain tasks when faced with the imminent threat of starvation (Kahneman, 2011; March and Shapira, 1992). In contrast to the 'affordable loss' logic, which does not focus on households at the subsistence level, the 'reasonable gain' logic operates at the survival threshold. This search may lead desperate individuals to initiate actions to start a new venture. All other factors being equal, they may seek new sources of income as a consequence of social structure disintegration. Therefore, we predict:

Hypothesis 1: Social structure disintegration will be positively related to an individual initiating action to start a new business.

Structural barriers may still impede, hinder, or hasten entrepreneurial behavior. The structural barriers important in our context are household income loss, a woman becoming the head of household, and access to community resources. Below, we develop hypotheses on the joint effect of social structure disintegration and structural factors on entrepreneurial behavior.

\section{Income lost and reasonable gain}

Unanticipated losses from a failed harvest or natural shocks will push a household to search for alternative sources of income. We expect that as a household loses income to unanticipated shocks, the likelihood of it pursuing entrepreneurial behavior will increase. We suggest that a loss may trigger household members to search for reasonable gains to ward off the threat of starvation. Households that suffer both social structure disintegration and income loss have very few resources with which to start a new business. In addition, due to the many hours of effort starting a business requires, doing so while caring for a family can be daunting. The break-up of a family may limit the strategic and emotional support a potential entrepreneur can receive (Renzulli, Aldrich and Moody, 2000) and lead to the loss of potential income with which to fund the business (Aldrich and Cliff, 2003). Although both losses may trigger the search for new opportunities, the simultaneous depletion of wealth and social support will leave a household with very few resources and without plausible avenues to assemble the resources needed for entrepreneurship. Thus, as the twin losses compound a household's misery, entrepreneurial behavior will decrease; that is, entrepreneurial behavior will decrease at an increasing rate. 
Social structure disintegration creates a strong motivation to search for any potential gains. When there are resources at hand that can replace the anticipated shortfall from a loss of social structure, it may hasten action to start a new business. The social structure loss causes a cognitive trigger to search for new sources of income. When the search for new opportunities is coupled with access to slack (reserve) resources, this enables the household to start a new business. Consequently, very few individuals are likely to maintain the status quo when their family is falling apart while they still have access to resources because they have not lost much income. The imminent threat of food shortage from inaction when a household experiences increasing social structure loss is a call to action, and slack resources engender action. Therefore, we predict that in conditions of desperate poverty:

Hypothesis 2: The positive relationship between an individual's social structure disintegration and their initiating action to start a new business is negatively moderated (weakened) by income loss.

\section{Household head gender and entrepreneurial behavior}

In patriarchal societies such as our Kenyan context, a woman only becomes the household head when the male head dies or becomes incapacitated. Consistent with this social norm, 90 percent of the male household heads in our Kenyan sample had a spouse, whereas only seven percent of the female household heads had a spouse, despite male and female household heads being of similar age (47 years). In this situation, a female household head must search for new income to fill the void left by her husband's absence. Therefore, female household heads may also be more willing to start a new business than male household heads. The analysis of how female household heads react to the loss of social structure compared with male household heads produces interesting predictions. Women tend to be more empathetic and feel emotion to a stronger degree than men (Fujita, Diener and Sandvik, 1991). The suffering of household members, especially children going hungry, is more likely to plague female household heads more than their male counterparts Evidence has shown that women in developing countries are more focused on their children's education than men, and may thus search more intensely for income (Gates 
Foundation, 2010). Therefore, with all other factors being comparable and at the same level of household income and wealth, a female-led household and a male-led household will react differently to the same level of social structure loss: women are more likely to act to end their family's suffering.

In addition, women often have fewer vices than men. They are less likely to abuse alcohol, gamble, and lose money on such pursuits (Kalichman et al., 2007). Therefore, female household heads that have the same level of income as male heads can put their households' resources to more productive use and may arrest the break-up of their families' social structure. Microcredit agencies generally perceive women to be better borrowers than men because they are less likely to default or spend loans on unproductive consumption (Karlan and Zinman, 2011). We suggest that even with the same resources as male-led households, women household heads are more likely to respond to social structure disintegration by engaging in entrepreneurship ${ }^{1}$. Therefore, in conditions of desperate poverty, we predict that:

Hypothesis 3: The positive relationship between an individual's social structure disintegration and their initiating action to start a new business will be positively moderated (strengthened) when women are household heads.

\section{Community institution membership and entrepreneurial behavior}

Membership in community institutions that offer access to group credit provides household heads with capital resources and shared risk. Increased access to capital will also increase perceptions of affordable loss (Dew et al., 2009). Microcredit agencies provide loans, especially in rural Kenya, mainly through group-based borrowing, in which all of the group members guarantee to repay the loan amount if one member defaults. Membership in community institutions may also allow households to garner information and increase the size and scope of their opportunities (Renzulli, Aldrich and Moody, 2000). Therefore, we anticipate that membership in a local credit community institution will increase the likelihood of entrepreneurial behavior.

\footnotetext{
${ }^{1}$ We are interested in explaining the initiation of action to start a new business. Conditional on entry into entrepreneurship, a male household head's network of connections may lead to more productive ventures (Carter, Brush, Greene, Gatewood and Hart, 2003). However, as women household head feel the pain of social structure loss more, can extract more out of the same level of resources, and can put the resources to more productive use than men, we expect higher rates of entry into entrepreneurship by female household heads.
} 
When the social structure disintegrates, the availability of resources and assistance from neighbors deteriorates, potentially pushing a household into the clutches of starvation. Social structure disintegration may cause the household head to focus on the potential gains that can be made by engaging in entrepreneurship. Access to community credit and shared risk pools are likely to be crucial factors in determining whether the household head can take the requisite steps to start a new business. Those with access to community resources may use the capital and advice that they receive from their community institution co-members to start new businesses. Therefore, we predict that social structure disintegration, when accompanied by access to community institutions, will hasten entry into entrepreneurship.

Hypothesis 4: The positive relationship between an individual's social structure disintegration and their initiating action to start a new business will be positively moderated (strengthened) by access to community resources.

\section{METHODS}

\section{Data collection}

We spent over three weeks in Kenya to train the data collection team, meet business owners and village leaders, engage local project partners, and ensure community commitment. We trained 20 data collectors to compile a complete census of all households. One of the authors spent three months in Kenya managing the training and data collection process to ensure the acquisition of high-quality data. We involved additional researchers in arranging meetings, coordinating efforts, interviewing, coding, and translating the data. This project took over 5,000 hours of effort.

Area administrators provided a list of all of the households in Kitonyoni and Mwania. We conducted baseline surveys in March 2011 to assess the socio-economic status of each household in these sub-locations. Each village manager within the sub-locations provided the team with a list of all of the households in their area of administration. Spot checks were also made of these lists to determine the exact number of households. We followed past studies in defining a household as a set of members who usually cook and eat together. We administered a questionnaire to each household head or another responsible member who was well-informed 
about the household's management. We held group discussions with residents and village leaders to ensure that our survey addressed the issues that were important to the local communities. We drafted the questionnaires in English and translated them into the local dialect of Kamba to ensure full engagement with the local population. The surveys were then reinterpreted into English to ensure consistency. Due to the lack of a postal system in these rural settings, the questionnaire was administered through face-to-face interviews. This tactic proved to be especially beneficial in these East African villages, where personal knowledge and interaction are highly valued.

\section{Dependent variable: Multi-category variable}

Our dependent variables consisted of the following: Baseline: This category consists of those household heads who had not started work on a new business nor expressed an intention to start a new business in the next three years (692 households met this classification, $67 \%$ of the sample). Intention: The next category consists of household heads who had expressed an intention to start a new business in the next three years, but had not yet started work on doing so (248 households, $23 \%$ of the sample). Outcome of interest: Initiating action to start a business. This category consists of individuals who expressed interest in starting a business in the next three years and had already started work on a new business (109 households, representing 10\% of the sample). For ease of communication we will refer to this category as 'initiating action.'

\section{Explanatory variables}

Our explanatory variables consisted of the following Social structure disintegration: Aldrich and Cliff (2003) encourage researchers to focus on significant changes to family structure- death, breakups, and single parent families — and the effect these changes have on entrepreneurship. We included both family and neighbor relationship changes in household social structure. We asked respondents about specific events that cause a household's social structure to change, namely changes in the composition of its working and adult members. We asked whether the household head had suffered a chronic/severe illness, death in the family, break-up with a spouse or partner, incarceration of a household member, contracted HIV/AIDS, or fought with neighbors 
in the previous three years. We counted the positive responses to these questions. The variable has a mean of 1.61 and a standard deviation of 1.27. The highest count of social structure shocks a household experienced is 7 .

Income lost. We measured total income lost by these households due to all types of shocks in the three years $(\mathrm{t}=-1,-2,-3)$ before the focal year $(\mathrm{t}=0)$. Over the three-year period, respondents reported that their households, on average, lost approximately $\$ 1,862$ USD from all the shocks they experienced. This amount is, hypothetically, the extra income the household could have earned had it not experienced any shocks in the three-year interval. It is an amount equivalent to approximately 30 percent of the household's total income. ${ }^{2}$ Past research has shown that it is not the amount of money lost that explains these households' next course of action, but rather how much the loss has taken them from a reference point. In our setting, the magnitude of the notional income lost in the past three years may not explain entrepreneurial behavior; however, the amount lost can be compared to a reference point in the form of the focal year's income. Households in the domain of loss-when the notional income lost over the past three years is greater than the income earned in the focal year-may be more likely to engage in entrepreneurship. Conversely, those in the domain of gain — when their income lost over the past three years is less than the income earned in the focal year-may be less likely to engage in entrepreneurship. In our sample, the average household income for the focal year was $\$ 1,434$. Thus, when we subtract the notional income that each household lost from shocks in the preceding three $(\$ 1,862)$ from the income that the average household earned in the focal year $(\$ 1,434)$, we get a deficit of $\$ 428$. This amount represents the notional amount that an average household is in deficit, as the notional income lost over the preceding three years' is greater than that which was earned in the focal year. Therefore, most households we surveyed could have been looking for opportunities to replenish their household income.

\footnotetext{
2 To put it in the context of a developed economy like that of the U.S., the mean American household income was $\$ 60,528$ according to the U.S. Census Bureau's 2004 Economic Survey. Income lost in our sample, then, would equate to approximately three percent of a U.S. household income.
} 
It is not surprising that studies from rural Africa have reported much higher rates of entrepreneurial intention. For now, we summarize the description of the variable as follows: When the variable is positive and increases in value, a household lost more in notional income than the income it earned in the focal year. As the variable turns negative, the household earned more in the focal year than the notional income it lost in the preceding three years. When the variable is zero, the household's focal year income was the same as the notional income it lost from shocks in the preceding three years.

Male household head: Male household heads were coded with a value of 1 and female household heads were coded with a value of 0. Community institution membership: This is an indicator variable that took a value of 1 if household members belonged to a community group used for raising loans; otherwise it was coded as 0 . Nearly 35 percent of the households had members who belonged to such community institutions.

\section{Control variables}

Our control variables consisted of the following: Age: We measured the age of the respondents in years since birth. Shocks: We controlled for three types of calamities befalling a household in addition to social structure disintegration: economic, natural, and other shocks. We counted the number of incidents that befell each household under each category in the past three years. Economic shocks: We counted the positive answers to whether or not the household had been subjected to a business failure, loss of salaried employment, non-payment of salary, the end of regular assistance, a rise in food prices, a rise in agricultural input prices, or the emigration of a household member. Natural shocks: We inquired whether or not the household had been exposed to natural disasters, such as drought, floods, crop diseases, or livestock death, and again counted the number of positive responses. Other shocks: This variable was designed to control shocks from household accidents, burglary, or any damages.

Family size: This variable counted the number of members in the household. Education: This indicator variable took a value of 1 if the head of the household had attended primary school 
and 0 if they had not. Household income: We measured the total income of the individuals in the household. Wealth: This variable captured the total value of a household's assets, including its house, farmland, livestock, business, and farm implements. We used a roster design to create a near-exhaustive list of household implements, tools, furniture, and other assets to document all household goods and assets. We then asked the respondents to calculate the value of each item if it were sold at the time of the interview. We used the total value of the household articles, the value of land and animal husbandry, and the value of homes and liquid assets to ascertain household wealth at the time of the survey. Business ownership: We used an indicator variable coded as 1 if the household already owned a business, and 0 if not.

Children in the household: Aldrich and Cliff (2003) suggest that older children in the early 19th century were used to help with household chores and were also employed by the community at large. In developing countries, families may still rely on older children in similar ways. We therefore counted the number of children in each household. Revising this variable using the age of the children to weight the simple count variable did not change the inferences for the theory variables. Savings: To control for financial perceptions of affordable loss, we asked each household head if their current household income allowed for savings. We asked the respondents how much they were able to save and coded their answers using a $1-5$ scale. The measure took a value of 1 if '[their] income [was] much more than expenses and [allowed] for savings' and 5 if '[their] income [was] less than [their] savings and [did] not allow for savings.' For ease of interpretation, we reverse-coded the measure.

\section{Estimation strategy}

To test our hypotheses, we compared those in the baseline condition with initiation of action to start a new business. Recall that those in the baseline condition were heads of households who had neither begun work on a new business nor had the intention to start one in the next three years. We compared those in the baseline condition and those who had started work on a new business-initiated action, which allowed us to test Hypotheses 1, 2, 3, and 4. We used a multiple 
logistic regression analysis that compared the baseline case, as it allowed us to account for the presence of the third category: those with mere intention, who have not taken action to start a new venture. The intuition was similar to running one Logit regression at a time. The advantage of using a multiple-logistic regression over a Logit regression is that it allowed us to categorize the sample's individuals into more than two conditions. Neither alternative-dropping the cases in the third category from the sample if using a simple Logit analysis, or force-fitting the third category into either of the two categories in a Logit analysis — was appealing for drawing a valid inference. Therefore, we used a multiple Logit regression analysis. We also conducted a robustness analysis using other estimation options.

\section{RESULTS}

In Table 1, we present the descriptive statistics for the variables used in the analysis and the correlations between the baseline and those who had taken action to start a new business. All of the correlations above 0.07 are significant at the $p<0.05$ level. In Table 2 , we report the multiple Logit estimations. Recall that the baseline condition consisted of household heads who had neither started work on a new business nor expressed an intention to start a new business in the next three years. We used Model 3, the full model, to test the hypotheses.

Before we describe the results of the hypotheses testing, we provide a brief explanation of how to interpret the results. Interpreting the main effects and moderators is not straightforward in a multiple Logit regression. In nonlinear models, the relationship between the change in the independent variable and the estimated change in the probability of the dependent variable cannot be inferred from the variable's coefficient. The interpretation depends on the change in magnitude of the explanatory variable, the starting points, and the values of the other variables in the estimation. Furthermore, the coefficient and significance of the interaction coefficient need not correspond to the direction of the hypothesized joint effect. The standard error of the interaction term conveys no direct information on statistical significance. Therefore, we follow Greene (2010), who suggests that attention should be paid to fit and statistical issues at the model 
building stage. Greene (2010) recommends that this interpretation should be completed by producing graphs across the range of explanatory variables to infer the economic significance of the predictions.

\section{INSERT TABLES 1 AND 2 HERE}

Hypothesis 1 predicts a positive relationship between social structure disintegration and initiating work on a new business. In Model 3, the social structure disintegration variable is positive but not significant $(b=0.035)$. We examined the effect of starting work on a new business across the range of social structure disintegration variables in our sample, as recommended by Greene (2010). We find a negative relationship between the very low values of the variable and the probability of entering entrepreneurship, until just above the mean of the variable. Past one standard deviation above the mean of the social structure disintegration variable, there appears to be an inversion of the negative relationship between this variable and starting a new business: in other words, the relationship becomes positive. Thus, as social structure disintegration takes higher values, it becomes more positively related to business formation. At lower values of the variable, social structure disintegration is negatively related to business formation. Consequently, as individuals suffer greater social structure loss, they are more likely to start work on a new business. Therefore, there is mixed support for Hypothesis 1 .

Hypothesis 2 considers income loss's moderating effect on the relationship between social structure disintegration and initiating action. The moderation of shock and income loss is negative and significant $(b=-0.056 ; p<0.10)$. In addition to the significant coefficient, the graph used to understand the economic effects of Hypothesis 2 reveals an impressive change in the probability of entering into entrepreneurship (Figure 3). When social structure disintegration has the mean value, there is no difference between low and high income loss. However, when social structure disintegration increases by one standard deviation, the probability of initiating action on a new business is 15 percent when the income loss is low, and half that (7\%) when the shock is 
high. Therefore, the economic change in initiating action is dramatic when social structure change is considered alongside income loss.

As predicted in Hypothesis 3, we find that gender-specifically, when the heads of households were women - has a negative moderation effect on social structure disintegration and business initiation (Model 3; $\mathrm{b}=-0.40, \mathrm{p}<0.05$ ). Female household heads were more likely than male household heads to enter into entrepreneurship as social structure loss increased (Figure 4). In terms of the economic effect, when social structure disintegration had a high value of 5 , women had an 18 percent probability of entering entrepreneurship, whereas men suffering similar social structure loss had only a 7 percent probability (this difference was significant at $p=0.038$ ).

Hypothesis 4 predicted the relationship between social structure disintegration and initiating action on a new business would be moderated by community membership (Model 3; b $=0.29 ; \mathrm{p}<0.10)$. When social structure disintegration is one standard deviation above the mean, those with access to community resources had a 19 percent probability of starting work on new businesses, whereas those without access to community resources had a six percent probability. Thus, there is a substantive decline in the likelihood of initiating action as social structure disintegration increases when households lack access to community resources (Figure 5). Hypothesis 4 is therefore supported.

INSERT FIGURES 2, 3, 4, AND 5 HERE

To summarize, three of the four predictions were empirically supported. The prediction that received mixed support was the main effect of social structure disintegration. We had predicted that the main effect of loss of social structure would be positively related to entrepreneurial activity in our context. However, the mixed support for this prediction is consistent with the theory we reviewed, suggesting that there are opposing forces acting on the entry into entrepreneurship. On one hand, social structure loss creates a downward pressure on available resources from the affordable loss perspective. On the other hand, this loss also creates 
a strong desire to seek out any possible gains. The effect of these opposing pressures can be best understood by examining the constraints on a household and its social structure change. Our results strongly suggest that social structure disintegration should be considered in conjunction with structural factors like income change, gender of the household head, and access to community resources. A household head's ability to actually start work on a new venture (and not merely intend to start a business) may be best understood in conjunction with the constraints that hinder or hasten start-up action.

\section{Corroborative evidence for reasonable gain}

To call on a mechanism of 'reasonable gain' requires a household to be at subsistence level and suffer a loss, and for the household head to change focus toward improving the financial position of the household. We predicted that when households at subsistence level experience a loss, the household members face starvation. In our sample, 97 percent of households had experienced at least some level of food shortage in the past year. Let us assume that those households that had experienced food shortages had also suffered social losses. If we examine the behavior of these households toward entrepreneurship, we find that the extent of starvation does not influence the initiation of start-up action; it is unaffected. When access to community credit is jointly considered with starvation, however, the picture changes dramatically; those with access to community credit initiate action to start new businesses at an increasing rate as their household experiences starvation (Figure 6). Thus, consistent with the reasonable gain mechanism, when a household faces food shortages, its head develops an intention to enter into entrepreneurship and when this is allied with access to credit, the head initiates action on a new business.

INSERT FIGURES 6 AND 7 HERE

Now consider the second component of the reasonable gain mechanism, the commitment to improving one's financial position. Household heads who expect their future income to improve are more likely to initiate action. We find that those who have access to community 
credit and expect their income to improve are more likely to initiate action (Figure 7). Therefore, when we examine household expectations, we find evidence consistent with the reasonable gain mechanism.

\section{Robustness checks}

Our robustness checks consisted of the following: Alternative dependent variables: We used two dependent variables and two estimations to check the robustness of our results for alternative specifications. First, we estimated a Logit regression of households that started new businesses against the baseline. The results for our main theory variables are similar to Table 2 . Second, we grouped those who had not acted in the same category as those in the baseline, and compared them with those who had started work on new businesses. Here again, results were consistent in significance and direction.

Data collection: We were careful to prevent the data analysis from being biased by issues such as common method bias, which is an unaccounted factor influencing the results. To mitigate such problems, we followed best practices in designing the survey. We asked fact-based questions and verified the facts with follow-up questions (Chang, van Witteloostuijn and Eden, 2010; Bettis et al., 2014). We followed up with the respondents who indicated that they had started activity by founding new businesses and verified what steps they had taken. Furthermore, we conducted Harman's one-factor test, which is used to infer whether common method bias exists in a sample. If there is substantial common method bias, then one factor will explain most of the variables in the sample in a principle component analysis test. Instead, eight factors have eigenvalues greater than 1 . The largest factor only explains about 11 percent, or a non-majority, of the variance. This analysis implies that there is not a substantial amount of common method bias in the data used to test the hypotheses (Podsakoff et al., 2003). 


\section{DISCUSSION}

\section{Affordable loss and reasonable gain}

We study a research setting atypical to those that have been studied in the developed world. Extreme poverty, and devastating social, financial, and environmental shocks are the norm in our research context. In such contexts of destitution, we suggest that the behavioral search for reasonable gain can predict entrepreneurial action. Our results reveal that this mechanism of reasonable gain can be triggered by loss of social structure, especially when accompanied by buffering factors such as access to community resources or low levels of income loss.

Conversely, when both social structure and access to resources are negatively affected, then there appears to be no ability to initiate action to start a business. Households that suffer income loss and experience social structure disintegration not only have a lower current stock of capital (affordable loss) but are also unlikely to receive support from kin to augment the resource pool. These households are the least likely to initiate a new business. Thus, we provide evidence of the conditions under which affordable loss and reasonable gain drive the initiation of new businesses, thus responding to calls for new theories and concepts that address grand challenges in business and entrepreneurship in impoverished settings (e.g., George, McGahan and Prabhu, 2012).

\section{Gender and entrepreneurship: women find a way to act}

Women who are the heads of their households may need to augment their households' income to replace the earnings lost by the absence of the male head. Female-led households had a 23 percent lower household income $(\mathrm{p}=0.004)$ than male-led households. However, there is no difference in wealth between the two types of households. Therefore, women-led households have similar levels of assets to draw upon should they want to engage in entrepreneurship. Further disintegration of the familial social structure hastens the need to augment the household's income, as can be observed by the increase in the likelihood of initiating a new business launch. As social structure disintegration increases from one standard deviation below the mean to one 
standard deviation above, the probability of female household heads' probability of initiating action to start a business increases by nearly 50 percent, from 8 to 13 percent.

It is interesting to note that male household heads have the diametrically opposite reaction. Male household heads in the same range of social structure disintegration are 43 percent less likely to take action to start a new business, the probability decreasing from 14 to 8 percent. Men shun entrepreneurship under adverse conditions, whereas women seem to be more likely to take up the gauntlet of entrepreneurship to restore their family's welfare. Studies that compare the performance of men and women who start businesses, especially in contexts such as ours, should take into account the extra barriers that women face.

\section{Limitations, boundary conditions and future research}

We do not assume that owning a business is beneficial for household income, nor do we assume that new businesses are good for society. Large sample evidence from developed countries has appeared to suggest that entrepreneurs, on average, earn less than similar individuals who remain employees. As an ex-post analysis, Kenyan census data enables us to report that households at similar levels of wealth who own businesses have 15 percent more income than their counterparts who do not. Thus, it appears that owning a business allows households in our context to extract most of their assets.

Another limitation of our study is that we do not seek to explain what types of businesses are founded, how the business ideas are organically developed, and how these businesses perform. Effectuation theory is a robust, descriptive, predictive, and empirically supported framework designed to answer these questions. We complement this theory by addressing the question of who expresses intention or initiates action to start a new business, rather than how individuals create or make entrepreneurial opportunities.

The boundary conditions for our study are as follows. First, in contexts in which the social structure of a household is stable, some of our findings on disintegration may not apply. We empirically observed households whose social structure was stable and that did not 
experience income shocks. The initiation levels of such households are therefore generalizable to other developed-country contexts. Second, conditions of desperate poverty may be fundamentally different from, and cannot be extrapolated to, developed country settings. Future researchers can consider the case of individuals in the developed world who are destitute and whether or not they react to social structure shocks as our evidence suggests. The preceding and more direct tests of the mechanism of reasonable gain are worthwhile endeavors for future researchers to pursue.

\section{CONCLUSION}

Limitations aside, this study makes two primary contributions to our current knowledge. We develop a perspective on how social structure change causes individuals to search for reasonable gain under conditions of desperate poverty. More importantly, we suggest that access to resources through membership in local community institutions and low levels of income loss hasten the initiation of a new business as social structure loss increases, which is consistent with our reasonable gains perspective. These results reinforce the importance of risk-sharing and micro-credit agreements for entrepreneurial growth.

We find that female household heads find ways to start new businesses when their social structure losses increase. Policymakers should therefore focus on interventions that support women through advice, resources, and networks. In addition, we find that households that own businesses enjoy a higher income, even at the same level of wealth, than households that do not. This finding calls for more studies on how businesses can enable households to get the best return from their limited resources in desperate poverty settings. More importantly, these findings endorse policy interventions to assess how micro-enterprise promotion can be usefully deployed for social development and growth. Simple as they may sound, these findings have significant importance to those living in desperate poverty, in which individual incomes fall below $\$ 2$ a day. 


\section{REFERENCES}

Aldrich HE, Cliff JE. 2003. The pervasive effects of family on entrepreneurship: toward a family embeddedness perspective. Journal of Business Venturing 18(5): 573-596.

Bettis R, Gambardella A, Helfat C, Mitchell W. 2014. Quantitative empirical analysis in strategic management. Strategic Management Journal 35(7): 949-953.

Carter N, Brush C, Greene P, Gatewood E, Hart M. 2003. Women entrepreneurs who break through to equity financing: the influence of human, social and financial capital. Venture Capital: An International Journal of Entrepreneurial Finance 5(1): 1-28.

Chang SJ, Van Witteloostuijn A, Eden L. 2010. From the editors: common method variance in international business research. Journal of International Business Studies 41(2): 178-184.

Department for International Development (DFID). 1999. Sustainable Livelihood Guidance Sheets. www.eldis.org/vfile/upload/1/document/0901/section2.pdf [23 November 2013].

Dercon S. 2004. Growth and shocks: evidence from rural Ethiopia. Journal of Development Economics 74: 309-329.

Dew N, Sarasathy S, Read S, Wiltbank R. 2009. Affordable loss: behavioral economic aspects of the plunge decision. Strategic Entrepreneurship Journal 3(2): 105-126.

Evans D, Jovanovic B. 1989. An estimated model of entrepreneurial choice under liquidity constraints. Journal of Political Economy 97: 808-827.

Fujita F, Diener E, Sandvik E. 1991. Gender differences in negative affect and well-being: the case for emotional intensity. Journal of Personality and Social Psychology 61(3): 427.

Gates Foundation. 2010. Pursue passion with a vengeance. http://ecorner.stanford.edu/authorMaterialInfo.html?mid=2997 [22 December 2014].

George, G., McGahan, AM., Prabhu, JC. 2012. Innovation for inclusive growth: Towards a theoretical framework and research agenda. Journal of Management Studies, 49(4): 661 - 683.

Gimeno J, Folta TB, Cooper, AC, Woo CY. 1997. Survival of the fittest? entrepreneurial human capital and the persistence of underperforming firms. Administrative Science Quarterly 42(4): 750-783.

Granovetter M. 1985. Economic action and social structure: the problem of embeddedness. American Journal of Sociology: 481-510.

Greene W. 2010. Testing hypotheses about interaction terms in nonlinear models. Economics Letters 107(2): 291-296.

Kahneman D. 2011. Thinking Fast and Slow. Farrar, Straus, and Giroux: New York, NY.

Kahneman D, Tversky A. 1979. Prospect theory: an analysis of decision under risk. Econometrica 47: 263-291.

Kalichman SC, Simbayi LC, Kaufman M, Cain D, and Jooste S. 2007. Alcohol use and sexual risks for HIV/AIDS in sub-Saharan Africa: systematic review of empirical findings. Prevention Science 8(2): 141-151.

Karlan D, Zinman J. 2011. Microcredit in theory and practice: using randomized credit scoring for impact evaluation. Science 332(6035): 1278-1284.

Kenya National Bureau of Statistics (KNBS). 2009. Kenya Census 2009.

Khavul S, Bruton GD, Wood E. 2009. Informal family business in Africa. Entrepreneurship Theory and Practice 33(6): 1219-1238.

Khayesi J, George G. 2011. When does the socio-cultural context matter? communal orientation and entrepreneurs' resource accumulation efforts in Africa. Journal of Occupational and Organizational Psychology 84: 471-492. 
Khayesi J, George G, Antonakis J. 2014. Kinship in entrepreneur networks: performance effects of resource assembly in Africa, Entrepreneurship Theory and Practice 38(6): 1323-1342.

Kiggundu MN. 2002. Entrepreneurs and entrepreneurship in Africa: what is known and what needs to be done. Journal of Developmental Entrepreneurship 7(3): 239-258.

Knight FH. 1921. Risk, Uncertainty, and Profit. Houghton Mifflin: New York, NY.

Kotha R, George G. 2012. Friends, family, or fools: entrepreneur experience and its implications for equity distribution and resource mobilization. Journal of Business Venturing 27: 525-543.

March JG, Shapira Z. 1992. Variable risk preferences and the focus of attention. psychological Review 99(1): 172.

Paul S, Sarma, V. 2013. Economic crisis and female entrepreneurship: evidence from countries in Eastern Europe and Central Asia (No. 13/08). CREDIT Research Paper.

Podsakoff PM, MacKenzie SB, Lee JY, Podsakoff NP. 2003. Common method biases in behavioral research: A critical review of the literature and recommended remedies. Journal of Applied Psychology 88(5): 879.

Read S, Song M, Smit W. 2009. A meta-analytic review of effectuation and venture performance. Journal of Business Venturing 24(6): 573-587.

Renzulli LA, Aldrich HE, Moody J. 2000. Family matters: gender, networks, and entrepreneurial outcomes. Social Forces 79(2): 523-546.

Reynolds P, Bosma N, Autio E, Hunt S, De Bono N, Servais I, Chin N. 2005. Global entrepreneurship monitor: data collection design and implementation 1998-2003. Small Business Economics 24(3): 205-231.

Ruef M. 2010. The Entrepreneurial Group: Social Identities, Relations, and Collective Action. Princeton University Press: Princeton, NJ.

Ruef M, Aldrich HE, Cartner NM. 2003. The structure of founding teams: homophily, strong ties, and isolation among US entrepreneurs. American Sociological Review 68(2): 195-222.

Sarasvathy SD. 2001. Causation and effectuation: toward a theoretical shift from economic inevitability to entrepreneurial contingency. Academy of Management Review 26(2): 243-263.

Thaler R. 1985. Mental accounting and consumer choice. Marketing Science 4(3): 199-214.

Vissa B. 2011. A matching theory of entrepreneurs' tie formation intentions and initiation of economic exchange. Academy of Management Journal 54(1): 137-158. 
Table 1: Descriptive statistics and correlations between baseline and initiation of action to start a new business

\begin{tabular}{|c|c|c|c|c|c|c|c|c|c|c|c|c|c|c|c|c|c|c|}
\hline & & Mean & S.d. & 1 & 2 & 3 & 4 & 5 & 6 & 7 & 8 & 9 & 10 & 11 & 12 & 13 & 14 & 15 \\
\hline 1 & Initiation of action to start a new business & .10 & .30 & 1 & & & & & & & & & & & & & & \\
\hline 2 & Income lost & 428.33 & $4,692.04$ & .02 & 1 & & & & & & & & & & & & & \\
\hline 3 & Male & .54 & .50 & -.01 & .00 & 1 & & & & & & & & & & & & \\
\hline 4 & Community credit membership & .35 & .48 & .15 & .03 & -.04 & 1 & & & & & & & & & & & \\
\hline 5 & Social structure disintegration & 1.61 & 1.27 & .00 & .11 & -.09 & -.01 & 1 & & & & & & & & & & \\
\hline 6 & Natural shocks & 2.40 & .74 & .09 & .06 & -.02 & .00 & .12 & 1 & & & & & & & & & \\
\hline 7 & Other shocks & .29 & .55 & -.03 & .09 & .00 & -.08 & .17 & .11 & 1 & & & & & & & & \\
\hline 8 & Economic shocks & 2.89 & 1.10 & .06 & .11 & .03 & -.07 & .26 & .26 & .19 & 1 & & & & & & & \\
\hline 9 & Family size & 5.52 & 2.31 & -.08 & .03 & .18 & .05 & .13 & .09 & .06 & .10 & 1 & & & & & & \\
\hline 10 & Children in the household & .81 & .96 & .05 & .01 & .01 & .03 & .28 & -.01 & .01 & .01 & .42 & 1 & & & & & \\
\hline 11 & Savings $\dagger$ & 1.23 & 1.10 & .02 & -.01 & .05 & .05 & -.06 & -.04 & -.08 & -.07 & -.11 & -.07 & 1 & & & & \\
\hline 12 & Education & 1.05 & .68 & .07 & -.02 & .27 & .10 & -.07 & -.05 & -.01 & .02 & .00 & .01 & .10 & 1 & & & \\
\hline 13 & Age & 47.71 & 22.54 & -.04 & .04 & -.01 & -.03 & .01 & -.04 & .00 & .01 & -.05 & -.03 & -.09 & -.04 & 1 & & \\
\hline 14 & Wealth (USD) & $12,281.85$ & $26,708.87$ & .01 & .05 & .05 & .06 & -.03 & -.01 & -.01 & -.04 & .02 & -.01 & .00 & .06 & -.01 & 1 & \\
\hline 15 & Income (USD annual) & $1,433.63$ & $2,162.70$ & .03 & -.25 & .10 & .16 & -.07 & .06 & -.01 & .01 & .02 & -.08 & .15 & .18 & .02 & .06 & 1 \\
\hline 16 & Household owns a business & .21 & .41 & .00 & .06 & .14 & .13 & -.04 & -.02 & .05 & .11 & .06 & -.02 & .14 & .13 & -.09 & .00 & .10 \\
\hline
\end{tabular}

All correlations $>.07$ are significant at $\mathrm{p}>.05 ;{ }^{\dagger}$ reverse coded to measure the extent of savings. 
Table 2: Multiple logit estimations of initiating action to start a business to the baseline

\begin{tabular}{|c|c|c|c|c|c|c|}
\hline & \multicolumn{6}{|c|}{ Initiating action } \\
\hline & $(1)$ & & $(2)$ & & (3) & \\
\hline Constant & $-2.55 * * *$ & $(0.60)$ & $-3.16 * * *$ & $(0.92)$ & $-5.54 * * *$ & $(1.67)$ \\
\hline Natural shocks & $0.39 * *$ & $(0.16)$ & $0.38 * *$ & $(0.16)$ & $0.35 * *$ & $(0.16)$ \\
\hline Other shocks & -0.24 & $(0.21)$ & -0.17 & $(0.22)$ & -0.16 & $(0.22)$ \\
\hline Economic shocks & 0.15 & $(0.10)$ & $0.18^{*}$ & $(0.10)$ & 0.16 & $(0.11)$ \\
\hline Family size & $-0.20 * * *$ & $(0.05)$ & $-0.21 * * *$ & $(0.06)$ & $-0.21 * * *$ & $(0.06)$ \\
\hline $\begin{array}{l}\text { Children in the } \\
\text { household }\end{array}$ & $0.35 * * *$ & $(0.12)$ & $0.36 * * *$ & $(0.12)$ & $0.35 * * *$ & $(0.12)$ \\
\hline Savings $\dagger$ & 0.018 & $(0.10)$ & 0.0071 & $(0.10)$ & 0.00035 & $(0.10)$ \\
\hline Education & $0.26 *$ & $(0.16)$ & 0.23 & $(0.16)$ & 0.24 & $(0.17)$ \\
\hline Age & -0.0051 & $(0.00)$ & -0.0050 & $(0.00)$ & -0.0053 & $(0.00)$ \\
\hline Wealth (USD ‘000) & 0.00092 & $(0.00)$ & 0.00033 & $(0.00)$ & 0.00057 & $(0.00)$ \\
\hline Income (USD ‘000) & 0.021 & $(0.04)$ & 0.012 & $(0.05)$ & 0.011 & $(0.05)$ \\
\hline $\begin{array}{l}\text { Household owns a } \\
\text { business }\end{array}$ & -0.018 & $(0.25)$ & -0.22 & $(0.27)$ & -0.26 & $(0.27)$ \\
\hline Theory Variables & & & & & & \\
\hline Income lost (USD ‘000) & & & 0.0094 & $(0.02)$ & $0.070^{*}$ & $(0.04)$ \\
\hline Gender (Male) & & & 0.031 & $(0.22)$ & $0.66^{*}$ & $(0.36)$ \\
\hline Community & & & $0.89 * * *$ & $(0.22)$ & 0.48 & $(0.36)$ \\
\hline Social structure & & & -0.041 & $(0.09)$ & 0.035 & $(0.15)$ \\
\hline Social * Income & & & & & $-0.056^{*}$ & $(0.03)$ \\
\hline Social $*$ Gender (Male) & & & & & $-0.40 * *$ & $(0.18)$ \\
\hline Social $*$ Community & & & & & $0.29 *$ & $(0.17)$ \\
\hline chi2 & 66.0 & & 89.0 & & 109.2 & \\
\hline Log likelihood & -864.1 & & -851.4 & & -841.2 & \\
\hline
\end{tabular}

The standard errors are in brackets; $* \mathrm{p}<.10, * * \mathrm{p}<.05, * * * \mathrm{p}<.01 ;{ }^{\dagger}$ reverse coded to measure the extent of savings.

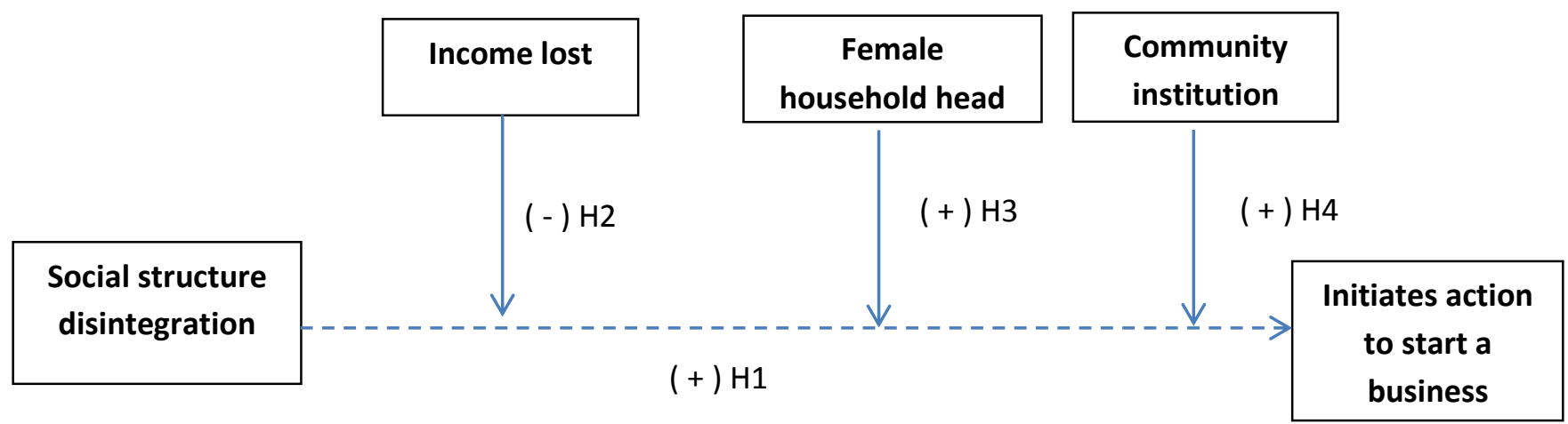

Figure 1: Model of social structure stability predicting who initiates action to start a business 


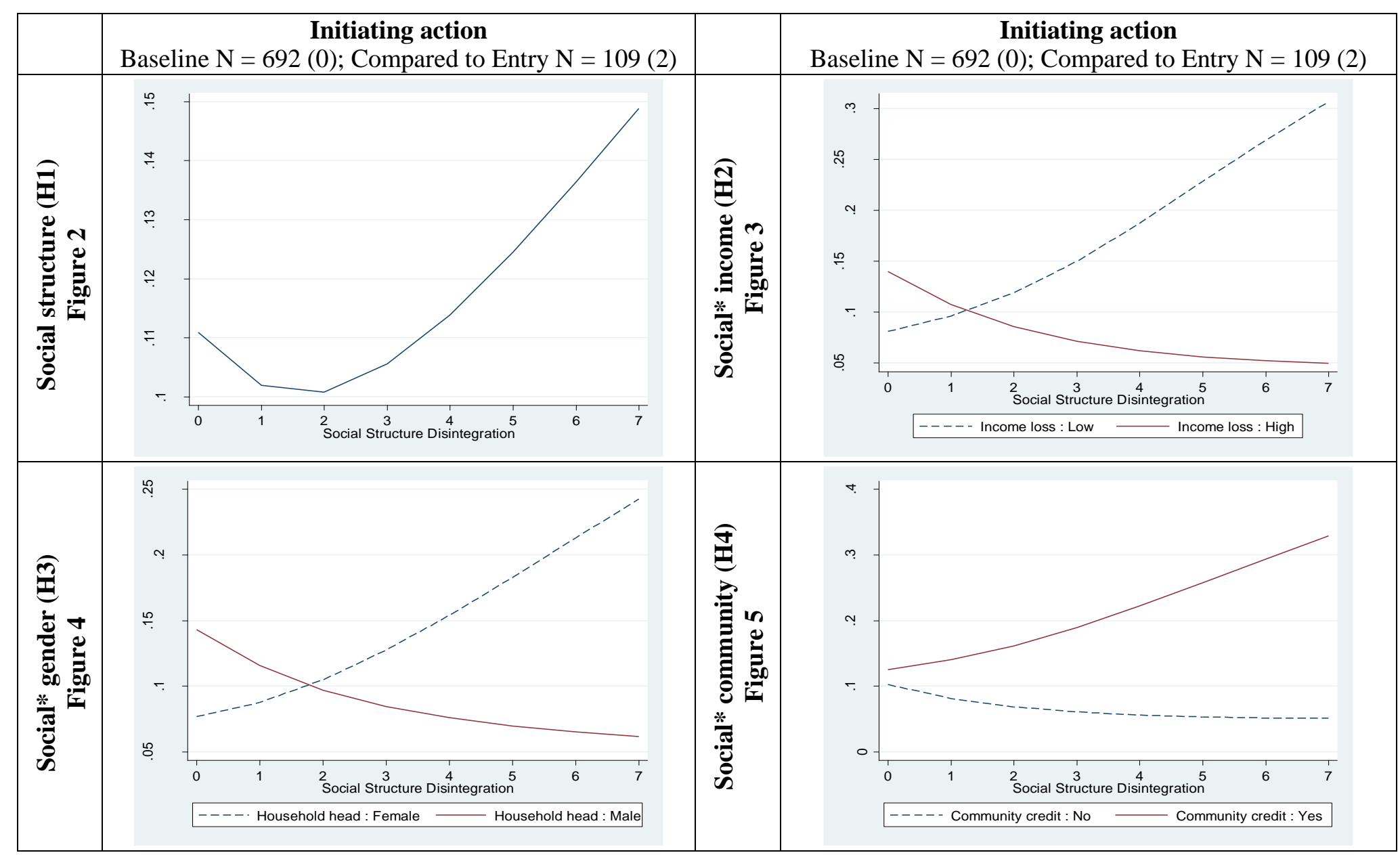

Figures 2-5: Results of hypotheses testing

\begin{tabular}{|c|c|c|c|}
\hline & $\begin{array}{c}\text { Initiating action } \\
\text { Bnitiating action }\end{array}$ & Baseline $\mathrm{N}=692(0) ;$ Compared to Entry $\mathrm{N}=109(2)$ \\
\hline & Baseline $\mathrm{N}=692(0) ;$ Compared to Entry $\mathrm{N}=109(2)$ & & \\
\hline
\end{tabular}

Figures 6 \& 7: Corroborative evidence 